\title{
A satellite-based investigation into the algae bloom variability in large water supply urban reservoirs during COVID-19 lockdown
}

\section{Enner Alcantara ( $\boldsymbol{\sigma}$ enner.alcantara@unesp.br)}

Sao Paulo State University

\section{Keyla Coimbra}

University of Campinas - Unicamp

Igor Ogashawara

Leibniz-Institute of Freshwater Ecology and Inland Fisheries

Thanan Rodrigues

Federal Institute of Education, Science and Technology of Pará State

Jose Mantovani

Sao Paulo State University

\section{Luiz Rotta}

Sao Paulo State University

\section{Edward Park}

National Institute of Education, Nanyang Technological University

Davi Gasparini Fernandes Cunha

University of Sao Paulo

\section{Research Article}

Keywords: Algae bloom, Cyanobacteria, Water supply, Water quality, COVID-19.

Posted Date: February 9th, 2021

DOl: https://doi.org/10.21203/rs.3.rs-211130/v1

License: (1) This work is licensed under a Creative Commons Attribution 4.0 International License. Read Full License 


\section{Abstract}

Here we report the first case study of the significant algae blooming in large reservoirs in relation to the COVID-19 lockdown in Sao Paulo, Brazil. Chlorophyll-a (Chl-a) and phycocyanin (PC) concentrations were analyzed in the Guarapiranga and Billings reservoirs, which supply daily water use for over 20 million people and receives treated wastewater. We employed field-calibrated Sentinel $2 \mathrm{MSI}$ and Landsat 8 OLI images to map the spatial patterns of Chl-aand PC over the two period: before (April, August and October 2019) and more than a month after the lockdown in Sao Paulo due to the rapid spread of the COVID-19 in Brazil (April 2020). We found a significant increase in algae blooming (both Chl-a and PC) in both reservoirs in April 2020, compared to the same month of 2019. We show that the episodic algae blooming is strongly related to the increased inflows of the residential wastewater from the surrounding watersheds, because the household water use has increased $~ 3.2 \%$ in April 2020, while the runoff into the reservoirs driven by the rainfall was much lower in 2020 compared to the previous year for the same month. In the case of Guarapiranga Reservoir, PC increased nearly 500\% in April 2020 compared to April 2019. Given the importance of Billings and Guarapiranga reservoirs for the water supply of the Metropolitan Region of Sao Paulo (MRSP), the abrupt occurrence of cyanobacteria blooms related to the state's lockdown should be considered a major concern for public and environmental health of the region. Although several environmental consequences have been reported due to the COVID-19 worldwide, this study is the first to report the impact of COVID-19 on the trophic state in the tropical reservoirs.

\section{Introduction}

In December 2019, health units in Wuhan City, Hubei Province, China, reported the occurrence of patients with pneumonia, of unknown cause, possibly epidemiologically associated with a seafood and live animals' market. On December 31st of that year, the Chinese Center for Disease Control and Prevention (China CDC) dispatched a team, along health authorities to conduct an epidemiological and etiological investigation (Zhu et al. 2020). The agent has been identified as a new coronavirus: SARS-COV-2.

In Brazil, the monitoring of cases began in January 2020. On January 22, the Emergency Operation Center (COE) of the Ministry of Health, coordinated by the Health Surveillance Secretariat, was activated to objectively plan and organize activities related to the control of local contamination, as well as international monitoring. A contingency plan was activated on January 27, and on February 3 the epidemic was declared a Public Health Emergency of National Importance (ESPIN) (Brazil, 2020).

The first confirmed cases of COVID-19 in Brazil were reported around the end of February in 2020 and referred to male individuals residing in the city of São Paulo. The cases were imported and until the beginning of March, evidence of local transmission of the virus was not found. The difficulty in containing the spread of the outbreak due to COVID-19 is that, although similar to the outbreaks caused by other coronaviruses, transmission can occur from asymptomatic cases; i.e., individuals who have not developed serious manifestations of the disease (Munster et al. 2020). As of June $7^{\text {th }}, 2020$, the number of confirmed cases and deaths in Brazil due to COVID-19 hit 676,494 and 36,044, respectively-with the 
largest number of confirmed case close to 90,000 in the Sao Paulo State, making the country one of the most affected by the pandemic.

Some authors analyzed the indirect effects of COVID-19 on the environment due to social distancing measures and the interruption of some economic activities worldwide (Aletta \& Osborn 2020; Muhammad et al. 2020; Xu et al. 2020). There has been a significant association between social distancing and better environmental conditions (e.g., improvement in air quality, environmental noise reduction and litter reduction in beaches), but also negative influences such as reduction of solid waste recycling and increasing contamination of water, land and air in other areas (Zambrano-Monserrate et al. 2020). More specifically regarding water quality, a decrease of approximately $16 \%$ in the suspended particulate matter in lake water (Yunus et al. 2020), an increase of up to 39\% in dissolved oxygen concentrations and a decrease in total coliforms in estuarine regions (Chakraborty et al. 2020, Mukherjee et al. 2020) were reported.

Since people's movement and industrial activities can be considered key drivers of pollution, it was expected at first, that the pollution loads would decrease, as highlighted by Yunus et al. (2020); however, they tried to analyze the lockdown impact on the water quality, using the suspended particulate matter (SPM) concentration, which is mainly driven by the rainfall regime associated with the anthropogenic activities such as land use patterns in the watershed. Therefore, we consider that SPM alone to be insufficient in assessing the direct effects of the lockdown at the watershed-scale.

In this paper, for the first time, we analyze the effect of lockdown due to COVID-19 on the reservoir water quality by mapping the Chlorophyll-a (Chl-a) and phycocyanin (PC) concentrations and the classification of the trophic status before and after the lockdown, based on multi-temporal remote sensing images. Similar approach was carried out for coastal areas in Indonesia (Adwibowo 2020), but further study of the impact of COVID-19 on freshwater quality has never been conducted. The Chl-a concentration is considered a general indicator for plankton biomass and the PC is characteristic of the presence of cyanobacteria (Simis et al. 2005). Cyanobacterial harmful algal blooms (cHABs) are considered a serious public health issue worldwide due to their ability to form dense biomass producing toxins; such toxins can cause dermatitis, gastrointestinal distress, liver failure or death of domestic and livestock animals when exposed to water with toxins (Stumpf et al. 2016; Mishra et al. 2019).

The São Paulo State Government declared partial lockdown on March 24, 2020, but the confirmed cases reached 143,073 contaminated people by June 08,2020 . This research seeks to address a question that, since the declaration of lockdown in the Metropolitan Region of São Paulo (MRSP), the water quality from reservoirs for water supply has improved? Therefore, the aim of this work is to analyze the phytoplankton (using Chl-a as a proxy) response to the human movement changes due to the COVID-19 lockdown in two reservoirs, which are a main source of drinking water. To our best knowledge, this is the first study to evaluate the trophic state changes in tropical reservoirs in Brazil following the social and economic restrictions imposed by the lockdown. This is especially crucial in São Paulo, because a 
complex system of different reservoirs is being used for drinking water supply to more than 20 million people living in the region.

\section{Materials And Methods}

\subsection{Study Area}

The study sites are the reservoirs of Guarapiranga and Billings, both placed in the MRSP, a very populated area that faces serious environmental issues, such as the lack of sanitation, high loads of pollutants coming from urban and industrial areas (Pires et al. 2015) (Figure 1). The two reservoirs are situated within eight cities: São Paulo, Itapecerica da Serra, Embu-Guaçu, São Bernardo do Campo, Diadema, Santo André, Ribeirão Pires and Rio Grande da Serra.

Guarapiranga and Billings reservoirs are located in the southwest and southeast regions of São Paulo, respectively. Guarapiranga receives water transposed from two other watersheds, Capivari and EmbuGuaçu rivers and the reversal of water from Billings reservoir to increase the water supply to the population. Billings is subdivided into tributaries, such as Rio Grande, Rio Pequeno, Rio Capivari and Taquacetuba (Figure 1).

Both reservoirs are used mainly for public water supply, however, the expansion of the urban mesh toward them compromise the water quality due to the discharge of domestic, industrial and agricultural waste. (Pires et al. 2015). Table 1 shows the basic characteristics of both reservoirs.

Table 1: Basic characteristics of Guarapiranga and Billings reservoirs.

\begin{tabular}{lll}
\hline & Guarapiranga & Billings \\
\hline Construction year & 1909 & 1927 \\
Average depth $(\mathrm{m})$ & 3.5 & 15 \\
Volume $\left(\mathrm{m}^{3}\right)$ & $1.9410^{8}$ & $1.210^{9}$ \\
Surface area $\left(\mathrm{km}^{2}\right)$ & 33 & 127 \\
Residence time (days) & 145 & 620 \\
Maximum depth (m) & 15 & 35 \\
\hline
\end{tabular}

Adapted from: Pires et al. (2005) and Cunha et al. (2013).

\subsection{COVID-19, population density and social isolation index}

The data about COVID-19, population density and social isolation index in São Paulo State was obtained from the São Paulo State Health Secretariat (https://www.seade.gov.br/coronavirus/) from March, 01 2020 to May, 08 2020. The social isolation index, which uses geolocation data provided by the nation's main telecom firms and shows the percentage of the population that abides by social isolation advice. 


\subsection{Image processing and Pigments models}

Satellite imagery from Sentinel-2 A and B and from Landsat 8 were used in this study. Sentinel 2 / Multispectral Instrument (MSI) Level $1 \mathrm{C}$ imagery processed by the European Space Agency were downloaded from Copernicus Open Access Hub (scihub.copernicus.eu/). Landsat 8 /Operational Land Imager (OLI) imagery processed by the United States Geological Service (USGS) were downloaded from the Earth Explorer (https://earthexplorer.usgs.gov/). The images used in this study are listed on Table 2 and covered the area of both Billings and Guarapiranga Reservoir.

Table 2: Satellite imagery used in this study

\begin{tabular}{crc}
\hline Satellite/ Sensor & Image ID & Date \\
\hline Sentinel 2 B / MSI & S2B_MSIL1C_20190427T131249 & 2019-04-27 \\
Sentinel 2 A / MSI & S2A_MSIL1C_20190830T131241 & 2019-08-30 \\
Sentinel 2B / MSI & S2B_MSIL1C_20191004T131249 & 2019-10-04 \\
Sentinel 2 A / MSI & S2A_MSIL1C_20200406T131241 & 2020-04-06 \\
Landsat 8 / OLI & LC08_L1TP_219076_20190427_20190508_01_T1 & 2019-04-27 \\
Landsat 8 / OLI & LC08_L1TP_219076_20190817_20190902_01_T1 & 2019-08-17 \\
Landsat 8 / OLI & LC08_L1TP_219076_20191004_20191018_01_T1 & 2019-10-04 \\
Landsat 8 / OLI & LC08_L1TP_219076_20200429_20200509_01_T1 & 2020-04-29 \\
\hline
\end{tabular}

Images from both sensors were atmospherically corrected with ACOLITE for the quantification of remote sensing reflectance above the water surface $\left(R_{r s}\right)$ via the dark spectrum approach (Vanhellemont and Ruddick, 2018; Vanhellemont, 2019). Further, using ENVI (Environment for Visualizing Images), Sentinel 2 / MSI $R_{r s}$ were converted into Chl-a (Equation 1) via the computation of the Normalized Difference Chlorophyll Index (NDCl, Mishra and Mishra, 2012) and Landsat 8 / OLI $R_{r s}$ were converted into phycocyanin (PC) concentration (Equation 2) using the virtual orange band (Castagna et al., 2020) and the calibration approach described by Kumar et al. (2020).

\subsection{Chl-a concentration retrieval and trophic status classification}

To retrieve the Chl-a concentration in both reservoirs we used the model proposed by Watanabe et al. (2019), which uses the Normalized Difference Chlorophyll Index (NDCl, Mishra and Mishra, 2012) as a proxy to estimate the Chl-a. This model was calibrated using 80 samples from the Tietê river cascading system, a neighboring reservoir with similar trophic state dynamics in Sao Paulo. 
Chl $-a=1093.2 \times N D C I^{2}+283.4 \times N D C I+25.947$

Where $N D C I=\frac{R_{r s}\left(\lambda_{2}\right)-R_{r s}\left(\lambda_{1}\right)}{R_{r s}\left(\lambda_{2}\right)+R_{r s}\left(\lambda_{1}\right)}$, and $\lambda_{1}=665 \mathrm{~nm}$ and $\lambda_{2}=705 \mathrm{~nm}$.

Based on the Chl-a values, the trophic state of each reservoir was classified based on Table 3.

Table 3: Trophic status classification for reservoirs. Adapted from CETESB (2017).

\begin{tabular}{cc}
\hline Trophic classification & Chl- $a\left(\mathrm{mg} \mathrm{m}^{-3}\right)$ \\
\hline Ultraoligotrophic & Chl- $a \leq 1.17$ \\
Oligotrophic & $1.17<$ Chl- $a \leq 3.24$ \\
Mesotrophic & $3.24<$ Chl- $a \leq 11.03$ \\
Eutrophic & $11.03<$ Chl- $a \leq 30.55$ \\
Supereutrophic & $30.55<$ Chl- $a \leq 69.05$ \\
Hypereutrophic & $69.05<$ Chl- $a$ \\
\hline
\end{tabular}

2.5. $P C$ concentration retrieval

The PC concentration retrieval was based on the ratio between the virtual orange band (Castagna et al., 2020) centered at $613 \mathrm{~nm}$ and the red spectral band centered at $655 \mathrm{~nm}$. According to Kumar et al. (2020) this ratio could be related to PC concentration () based on the following relationship:

$$
P C=3 \times 10^{7} \times e-11.68 \times B D
$$

Where $B D=\frac{R_{r s}(613)}{R_{r s}(655)}$

\section{Results}

\subsection{Confirmed cases and death by COVID-19 in the Guarapiranga and Billings reservoirs area}

Most of the confirmed cases and deaths occurred within the city of São Paulo (11,869,660 inhabitants), followed by the city of São Bernardo do Campo (812,086 inhabitants); on the other hand, city of EmbuGuaçu (68,053 inhabitants), Ribeirão Pires (118,968 inhabitants) and Rio Grande da Serra (49,816 inhabitants) presented the lowest numbers of cases and deaths (Figure 2).

The city of São Paulo is by far the most affected with COVID-19 (up to 26 May, 2020) with 47,554 confirmed cases and 3,691 deaths. On the other hand, the city of Diadema reported 909 confirmed cases 
and 64 deaths. The social distancing in São Paulo in 06 of March was $27 \%$ and in 26 may was $48 \%$ and in Diadema was $33 \%$ and $43 \%$, respectively.

\subsection{Chl-a spatial distribution}

The remotely sensed estimation of Chl-a in Guarapiranga and Billings reservoirs is presented in Figure 3. The Chl-a maps reveal that the Guarapiranga reservoir showed relatively low temporal variability throughout the time of analysis; on the other hand, Billings showed a more variable pattern. In the Billings reservoir, the regions near the cities of São Paulo and São Bernardo do Campo showed to be more variable. When comparing April 2019 and April 2020 (more than a month after the partial lockdown), Billings showed a remarkable increase in its mean Chl-a concentration of $36.95 \mathrm{mg} \mathrm{m}^{-3}$ (Table 4), even with relatively less rainfall (and thus less runoff into the reservoir) (Figure 1B).

The trophic status maps showed that Guarapiranga in April 2019 was classified mostly as eutrophic, while in April 2020 was mostly classified as hypereutrophic. Billings reservoir was mostly classified as hypereutrophic, but if we compare April of both years, the area covered by the hypereutrophic class has also significantly increased.

The boxplot graphs derived from the maps of Chl-a concentration for Guarapiranga and Billings are plotted in Figure 4. Guarapiranga showed the highest Chl-a concentration (164.26 mg. $\mathrm{m}^{-3}$ ) in April 2020 and the lowest $\left(29.53 \mathrm{mg}^{-3}\right.$ ) in October 2019 . The highest variability was also observed in April 2020 with a standard deviation of $31.23 \mathrm{mg} \cdot \mathrm{m}^{-3}$, showing an increasing trend after the partial lockdown. In the same fashion Billings depicted the highest Chl-a concentration also in April 2020 (587.63 mg. $\mathrm{m}^{-3}$ ) and the lowest in October 2019 (30.74 $\mathrm{mg}^{-3} \mathrm{~m}^{-3}$; the highest standard deviation was observed in April 2020 $\left(121.42 \mathrm{mg} \cdot \mathrm{m}^{-3}\right)$ and the lowest in October $2019\left(66.00 \mathrm{mg} \cdot \mathrm{m}^{-3}\right)$. An increase of the Chl-a concentration was also observed after the partial lockdown.

To verify if the mean Chl-a concentration in April 2019 and 2020 are statistically different, a paired Student's $t$-test was applied. The results showed that for both reservoirs the $p$-value was lower than the significance level of $5 \%$ (Table 4), which confirms that they are different. The $t$-test also showed that the difference in Billings reservoirs was far more pronounced than in Guarapiranga. All the evidence presented in this section indicates that the watershed discharge into the reservoir has increased that facilitated the algae blooming, which is possibly related to the lockdown in the area.

Table 4: Paired Student's t-test between maps of Chl-a from April 2019 and April 2020 for both reservoirs. 
Paired Student's t-test

\begin{tabular}{ccccc}
\hline Reservoirs & Mean difference & $95 \%$ conf. & T-value & $p$-value \\
Guarapiranga & 20.65 & $(14.79 ; 26.51)$ & -7.05 & $<0.0001$ \\
\hline Billings & 36.95 & $(18.48 ; 55.41)$ & -3.97 & $<0.0001$ \\
\hline
\end{tabular}

\subsection{Phycocyanin spatial distribution}

The PC maps, as a proxy of cyanobacterial presence, are displayed in Figure 5. In April 2019 both reservoirs showed high values of PC concentration (mean 250), which was reduced in October 2019, which then increased again in April 2020 (means 1,000 and 550, respectively for the Guarapiranga and Billings). The Guarapiranga reservoir is mostly affected by São Paulo, Itapecerica da Serra and EmbuGuaçu, and the maps showed that the area near Embu-Guaçu showed the highest concentrations. On the other hand, Billings reservoir showed the highest PC concentration in the region near Rio Grande da Serra.

The PC concentration boxplot graphs (Figure 6) showed that in Guarapiranga, the highest values were observed in April 2020 ( 2000,00) and the lowest in October 2019 (17.78). For Billings, high values were observed in April 2020 (2,400) and the minimum was presented in October 2019 (27). The highest variability was observed in April 2020 (609.27 ) and according to Figure 5d, the highest values were observed in the Rio Grande branch, east portion of the reservoir and close to the municipality of Ribeirão Pires. This river was separated from the main body of the reservoir in order to maintain a proper water quality. However, the region suffers from the influences of domestic and industrial wastes from Ribeirão Pires and São Bernardo do Campo municipalities (CETESB 2002).

The paired Student's $t$-test for PC for both reservoirs also confirmed that the mean PC concentration between April 2019 and April 2020 were statistically different (Table 5). The highest mean difference was observed for Guarapiranga reservoir. The result of a comparative analysis of the PC concentration in this section also indicates that the rate of algae blooming was abnormally high during April compared to the previous year.

Table 5: Paired Student's $t$-test between maps of PC from April 2019 and April 2020 for both reservoirs. 
Paired Student's t-test

\begin{tabular}{ccccc}
\hline Reservoirs & Mean difference & $95 \%$ conf. & T-value & $p$-value \\
Guarapiranga & 796.60 & $(639.35 ; 953.87)$ & -10.15 & $<0.0001$ \\
\hline Billings & 355.31 & $206.60 ; 504.03)$ & -4.76 & $<0.0001$ \\
\hline
\end{tabular}

\section{Discussion}

The lockdown due to the COVID-19 has different consequences for public health and environmental conditions, which are unique for each location worldwide. In Venice (Italy), for example, the significant reduction in boat traffic and tourism activities has led to a decrease in sewage discharge in the local channels (Braga et al. 2020). According to the authors, this partially explained the greater water transparency in the Venice Lagoon following the lockdown measures. On the other hand, the effects of the COVID-19 lockdown in the MRSP probably increased the production of domestic wastewater. Consequently, our study reported some possible consequences on the water quality of the water supply reservoirs. Satellite imagery were used for the estimation of algal pigments such as Chl-a and PC, as well as mapping of trophic index within the area of the two most important reservoirs in the Sao Paulo State. The retrieved values of Chl-a agreed with previous studies which also showed that the concentration in Billings reservoir is higher than in Guarapiranga reservoir (Pires et al., 2015).

The trophic index also agreed with previous research which showed that Guarapiranga is supereutrophic while Billings is hypereutrophic (Gemelgo et al., 2009). According to CETESB (2019), the Billings reservoir has high degree of eutrophication, with most of the monitored points classified from supereutrophic to hypereutrophic, whereas in the Guarapiranga the points were classified as supereutrophic. It is important to highlight that previous research was based on point sampling while in this study, the use of remote sensing allowed us to evaluate the spatial distribution patterns of the algae blooming over the entire area of both reservoirs. As we observed the spatially varying patterns of the algae blooming over the large reservoirs, a point sampling-based study such as Piris et al. (2015), is limited in holistic assessment of the Chl-a patterns since their study sampled only one area in the South of both reservoirs where Chl-a concentrations were lower (Figure 3).

The PC concentration estimated by remote sensing showed the dominance of cyanobacteria in both reservoirs. The comparison between the image from April of 2019 and 2020 showed that there was a significant increase in the PC concentration in both reservoirs (Figure 5). This suggests that after the lockdown, cyanobacteria in the reservoirs increased. A similar effect was observed by Pal et al. (2020) who verified that the standing stock of phytoplankton in Diamond Harbour station along the Hooghly estuary (India) was higher in April, 2020 compared to 2019 and 2018. For the authors, the cutoff of discharges from industries, tourism and water transport systems, due to the lockdown, accelerated the 
growth of phytoplankton species because of the removal of stress posed by pollution from point and nonpoint sources.

According to Pal et al. (2020), the SPM and oil film associated in the aquatic ecosystem, common in estuarine water of Indian Sundarbans, inhibits the solar energy to penetrate in the water column, thereby posing a negative impact on phytoplankton. In the case of Billings and Guarapiranga reservoirs, the discharge of domestic wastewater has increased due to the lockdown which likely contributed to the occurrence of cyanobacteria blooms in the water surface. The superintendent of SABESP (company responsible for water supply in São Paulo) reported that there was an increase of $3.2 \%$ in water consumption in April 2020 when compared to April 2019 (Souza, 2020). SABESP decided to increase the residential water supply during the quarantine from 130 to 137 liters per person (SIGRH, 2020). Considering the importance of Billings and Guarapiranga reservoirs for the water supply of the MRSP, the occurrence of cyanobacteria blooms is a major concern for public and environmental health. Carvalho et al. (2007) detected the presence of 17 species of cyanobacteria in both reservoirs where 9 of them were potentially toxic. Additionally, authors investigated a cyanobacteria bloom which occurred in August 2001, in Guarapiranga reservoir. The toxic extract from the waters from this specific bloom were injected to animals which presented symptoms of poisoning similar to those described for Microcystis and died in a time ranging from 50 minutes to two hours. This highlights the importance of monitoring algal pigments for water quality purposes. Finally, the lockdown caused by COVID-19 in the MRSP possibly decreased the water quality from these urban reservoirs.

\section{Conclusions}

Although several environmental consequences reported due to the COVID-19, the trophic state change in the reservoir have not been analyzed. In this paper, we report the first case of increased algae bloom in reservoirs related to the COVID-19 lockdown in Sao Paulo, Brazil. We analyzed Chlorophyll-a (Chl-a) and phycocyanin (PC) concentrations in the Guarapiranga

and Billings reservoirs that supplies daily water use for over 20 million people and receives treated wastewater. Chl-a and PC were mapped using field-calibrated Sentinel 2 MSI and Landsat 8 OLI images over the two periods, before (April, August and October 2019) and more than a month after the lockdown (April 2020) in São Paulo. We found a statistically significant increase of algae blooming (for the both parameters) in both reservoirs in April 2020 compared to the same month of 2019. In the case of Guarapiranga Reservoir, PC increased nearly 500\% in April 2020 compared to April 2019, although the runoff driven by the rainfall was much lower in April 2020. Our results indicate that after the lockdown, cyanobacteria in the reservoir's surface have dramatically increased which we attribute to the increased inflows of wastewater from the surrounding watersheds. Given the importance of Billings and Guarapiranga reservoirs for the water supply of the MRSP, the occurrence of cyanobacteria blooms is a major concern for public and environmental health of the region.

\section{Declarations}


Competing Interest: The authors declare no competing interests.

\section{Acknowledgements}

E.A. acknowledge the São Paulo Research Foundation (FAPESP) under grant 19/00259-0. L.H.R. acknowledges the Coordination for the Improvement of Higher Education Personnel - (CAPES) for the postdoctoral fellowship PNPD $n^{\circ} 88882.317841 / 2019-01$. E.P. acknowledges the SUG-NAP (3/19 EP) grant at the Nanyang Technological University.

\section{References}

Adwibowo, A. Does social distancing have an effect on water quality? An evidence from Chlorophyll-a level in the water of populated Southeast Asian Coasts. Preprints 2020, 2020050091.

Aletta, F., Osborn, D. The COVID-19 global challenge and its implications for the environment - what we are learning. UCL Open: Environment. 2020, (1):05.

Braga, F., Scarpa, G.M., Brando, V.E., Manfè, G., Zaggia, L. 2020. COVID-19 lockdown measures reveal human impact on water transparency in the Venice Lagoon. Science of the Total Environment 736, 139612.

Brazil. Ministry of Health - COVID19 - Coronavirus Panel. https://covid.saude.gov.br/. (2020), Accessed 30 ${ }^{\text {th }}$ May 2020.

Carvalho, L.R., Sant'Anna, C.L., Gemelgo, M.C.P., Azevedo, M.T.P. (2007). Cyanobacterial occurrence and detection of microcystin by planar chromatography in surface water of Billings and Guarapiranga Reservoirs, SP, Brazil. Brazilian Journal of Botany, 30(1), 141-148.

Castagna, A.; Simis, S.; Dierssen, H.; Vanhellemont, Q.; Sabbe, K.; Vyverman, W. Extending Landsat 8: Retrieval of an Orange contra-Band for Inland Water Quality Applications. Remote Sens. 2020, 12, 637.

CETESB. Avaliação da qualidade das águas interiores no estado de São Paulo 2002. São Paulo, 2003. (Série Relatórios) Available in:< http://www.cetesb.sp.gov.br/agua/aguas-superficiais/35- publicacoes-/relatorios>. Access in: 03/06/2020.

CETESB - Companhia Ambiental do Estado de São Paulo, 2017. Qualidade das águas interiores no estado de São Paulo - 2016.. https://cetesb.sp.gov.br/aguas-interiores/publicacoes-e-relatorios/ (acessed 1 April 2020).

Chakraborty, S., Mitra, A., Pramanick, P., Zaman, S., Mitra, A. Scanning the water quality of lower Gangetic delta during COVID-19 lockdown phase using dissolved oxygen (DO) as proxy. NJUS Journal of Regulatory Studies, Special Issue on COVID-19 (2020), 69-74. 
Cunha, D.G.F., Calijuri, M.C., Lamparelli, M.C. A trophic state index for tropical/subtropical reservoirs $\left(\mathrm{TSI}_{\mathrm{tsr}}\right)$. Ecological Engineering. 60 (2013). 126-134.

Gemelgo, MCP, Mucci, JLN, Navas-Pereira, D. Population dynamics: seasonal variation of phytoplankton functional groups in Brazilian reservoirs (Billings and Guarapiranga, São Paulo). Braz. J. Biol., 69(4), 1001-1013, 2009

Kumar, A.; Mishra, D.R.; llango, N. Landsat 8 Virtual Orange Band for Mapping Cyanobacterial Blooms. Remote Sens., 12, 868, 2020.

Mishra, S.; Mishra, D.R. Normalized difference Chlorophyll index: A novel model for remote estimation of Chlorophyll a concentration in turbid productive waters. Remote Sens. Environ., 117, 394-406, 2012.

Mishra, S., Stumpf, R.P., Schaeffer, B.A., Wedell, P.J., Loftin, K.A., Meredith, A. Measurement of cyanobacterial bloom magnitude using satellite remote sensing. Scientific Reports. 9 (2019), 18310.

Muhammad, S., Long, X., Salman, M. COVID-19 pandemic and environmental pollution: a blessing in disguise? Science of the Total Environment 728, (2020). Article 138820.

Mukherjee, P., Pramanick, P., Zaman, S., Mitra, A. Eco-restoration of River Ganga water quality during COVID-19 lockdown period using Total Coliform (TC) as proxy. NJUS Journal of Regulatory Studies, Special Issue on COVID-19 (2020), 75-82.

Munster, V.J., Koopmans, M., Van Doremalen N., Van Riel, D., Wit, E. A novel coronavirus emerging in china - key questions for impact assessment. New England Journal of Medicine. 382 (2020). pp. 692-4.

Pires, D.A., Tucci, A., Carvalho, M.C., Lamparelli, M.C. Water quality in four reservoirs of the metropolitan region of São Paulo, Brazil. Acta Limnologica Brasiliensia. 27, (2015), 370-380.

São Paulo. São Paulo State - Social Isolation Intelligent Monitoring System. https://www.saopaulo.sp.gov.br/coronavirus/isolamento/ (2020), Accessed 14 May 2020.SEADE. Coronavirus. https://www.seade.gov.br/coronavirus/ (2020), Accessed 30 th $M a y 2020$.

SIGRH - Sistema Integrado de Gerenciamento de Recursos Hídricos do Estado de São Paulo. 2020. http://www.sigrh.sp.gov.br/pageitems/450/news/10417

Simis, S.G.H., Peters, S.W.M., Gons, H.J. Remote sensing of the cyanobacterial pigment phycocyanin in turbid inland water. Limnology and Oceanography. 50 (2005). 237-245.

Souza, Roberto Tavares. Interview in Radio Cultura FM, May 13, 2020.

http://culturafm.cmais.com.br/oito-em-ponto/o-consumo-de-agua-aumentou-na-quarentena.

Stumpf, R.P., Davis, T.W., Wynne, T.T., Graham, J.L., Loftin, K.A., Johengen, T.H., Gossiaux, D., Palladino, D., Burtner, A. Challenges for mapping cyanotoxin patterns form remote sensing of cyanobacteria. Harmful 
Algae. 54 (2016), 160-173.

Vanhellemont, Q.; Ruddick, K. Atmospheric correction of metre-scale optical satellite data for inland and coastal water applications. Remote Sens. Environ., 216, 586-597, 2018.

Vanhellemont, Q. Adaptation of the dark spectrum fitting atmospheric correction for aquatic applications of the Landsat and Sentinel-2 archives. Remote Sens. Environ., 225, 175-192, 2019.

$\mathrm{Xu}, \mathrm{H}$. et al. Possible environmental effects on the spread of COVID-19 in China. Science of The Total Environment. 731. (2020). 139211.

Yunus, A.P., Masago, Y., Hijioka, Y. COVID-19 and surface water quality: Improved lake water quality during the lockdown. Science of The Total Environment. 731, (2020). Article 139012.

Zambrano-Monserrate, M.A., Ruano, M.A., Sanchez-Alcalde, L. Indirect effect of COVID-19 on the environment. Science of The Total Environment. 728, (2020). Article 138813.

Zhu, N. et al. A novel coronavirus from patients with pneumonia in China. New England Journal of Medicine. 382 (2020). pp. 727-733.

\section{Figures}




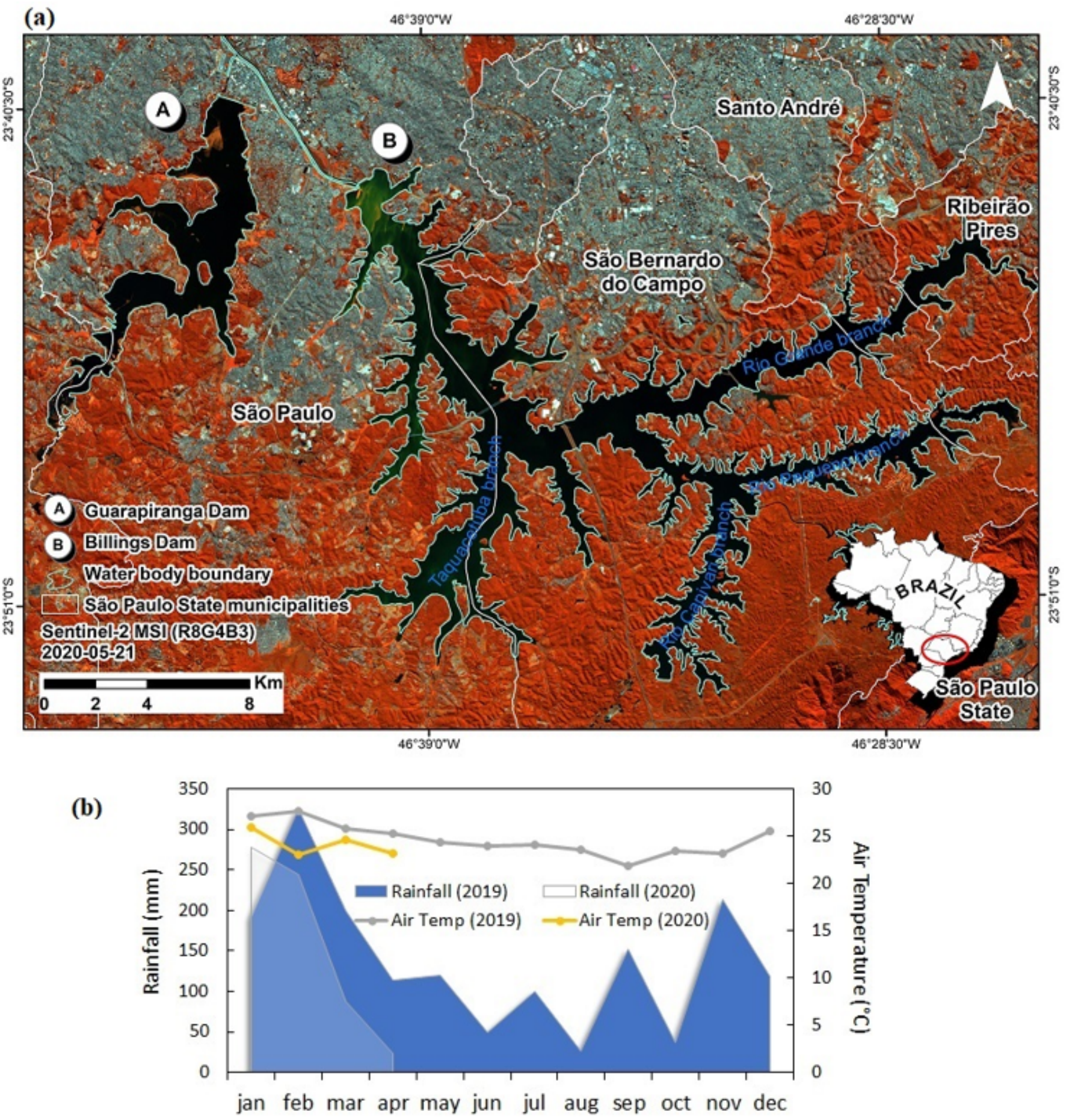

\section{Figure 1}

(a) A portion of the MRSP highlighting the reservoirs of Guarapiranga and Billings. (b) Average monthly rainfall $(\mathrm{mm})$ and air temperature $\left({ }^{\circ} \mathrm{C}\right)$ acquired from Giovanni NASA's database (https://giovanni.gsfc.nasa.gov/giovanni/). 


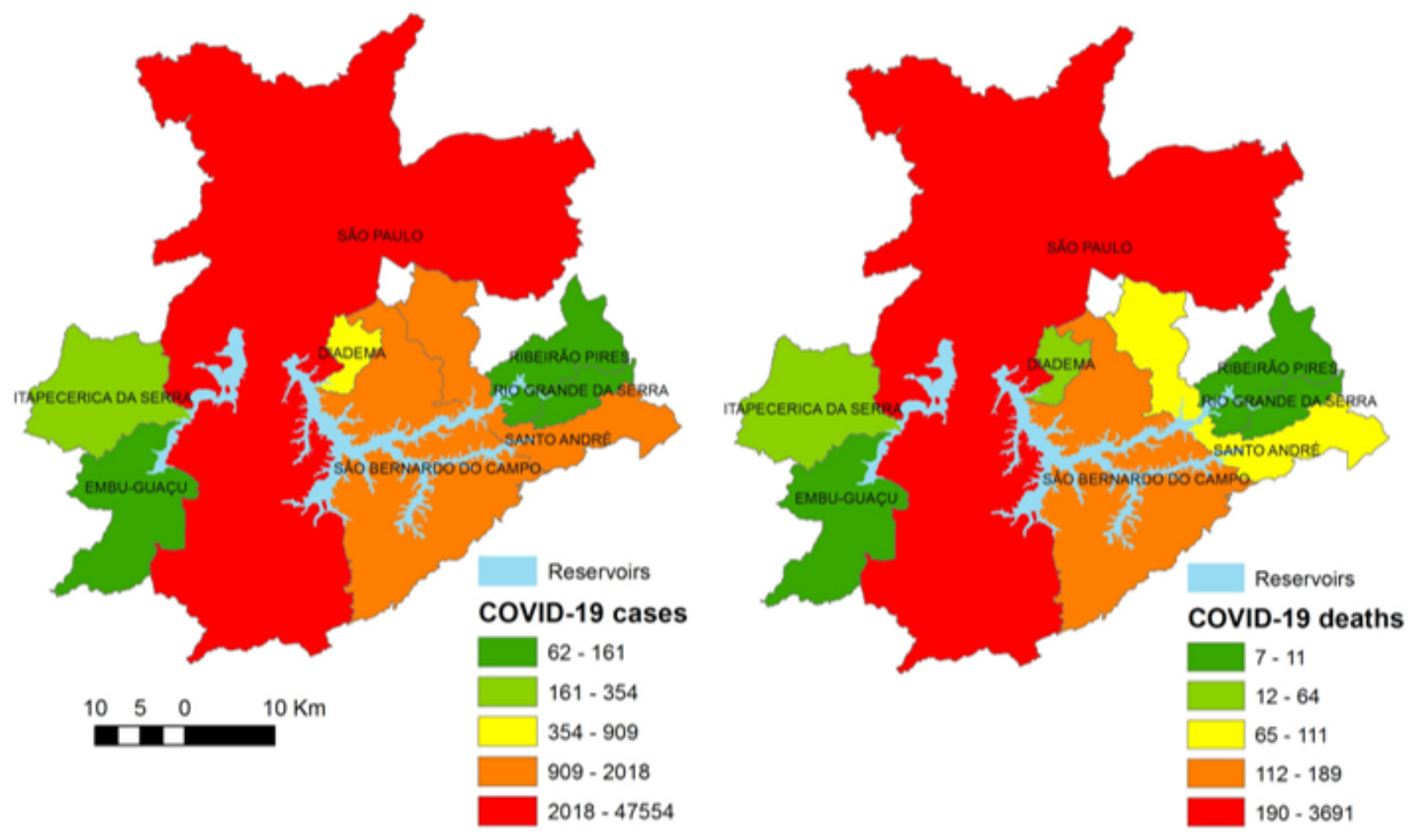

Figure 2

Spatial distribution of cases and deaths of COVID-19 (up to 26 May, 2020) in the region of influence of Guarapiranga and Billings reservoirs. 


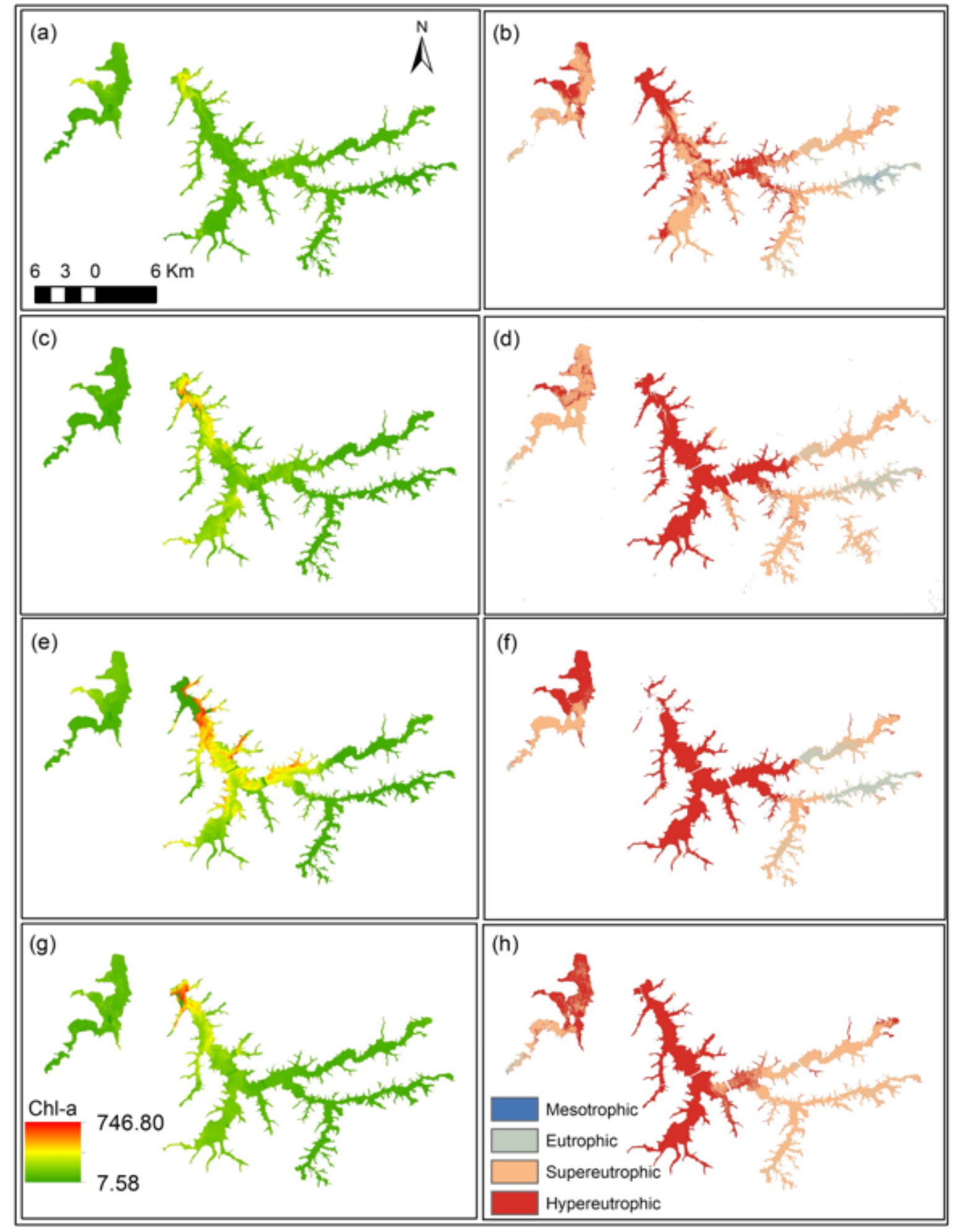

Figure 3

Maps from Guarapiranga and Billings reservoir showing the Chl-a concentration $(\mathrm{mg} / \mathrm{m} 3)$ and the Trophic Status for the dates (a), (b) April 27, 2019, (c), (d) August 30, 2019, (e), (f) October 04, 2019 and (g), (h) April 06, 2020, respectively. 

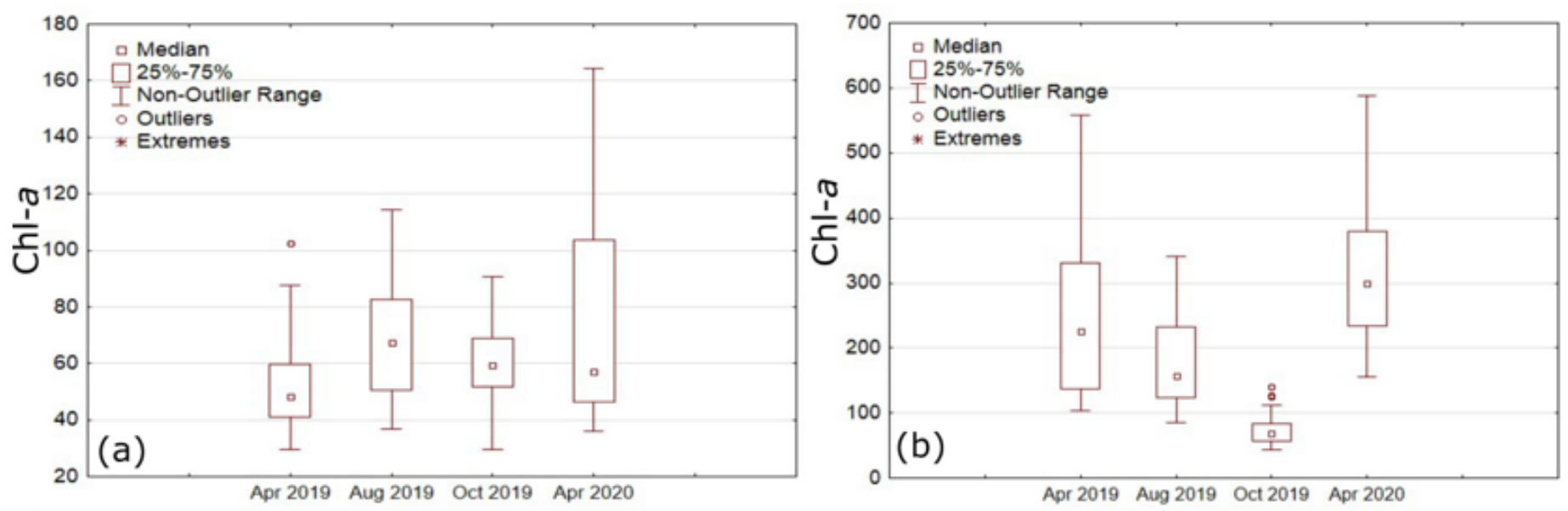

\section{Figure 4}

Boxplot for Chl-a concentration ( $\mathrm{mg} / \mathrm{m} 3$ ) in (a) Guarapiranga and (b) Billings reservoirs.

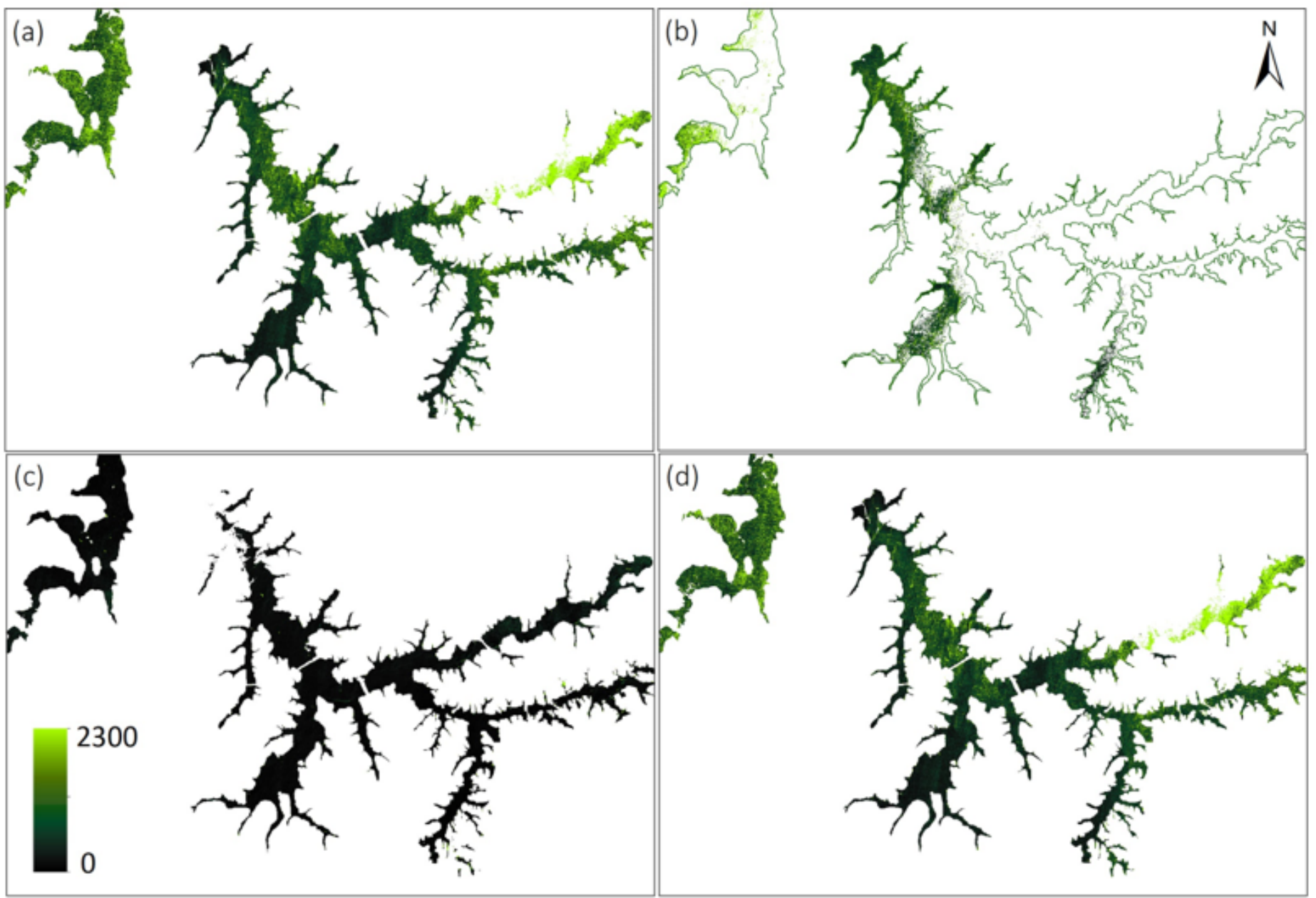

Figure 5

Maps from Guarapiranga and Billings reservoir showing the PC concentration ( $\mu \mathrm{g} / \mathrm{L})$ for the dates (a) April 27, 2019, (b) August 30, 2019, (c) October 04, 2019 and (d) April 06, 2020, respectively. 

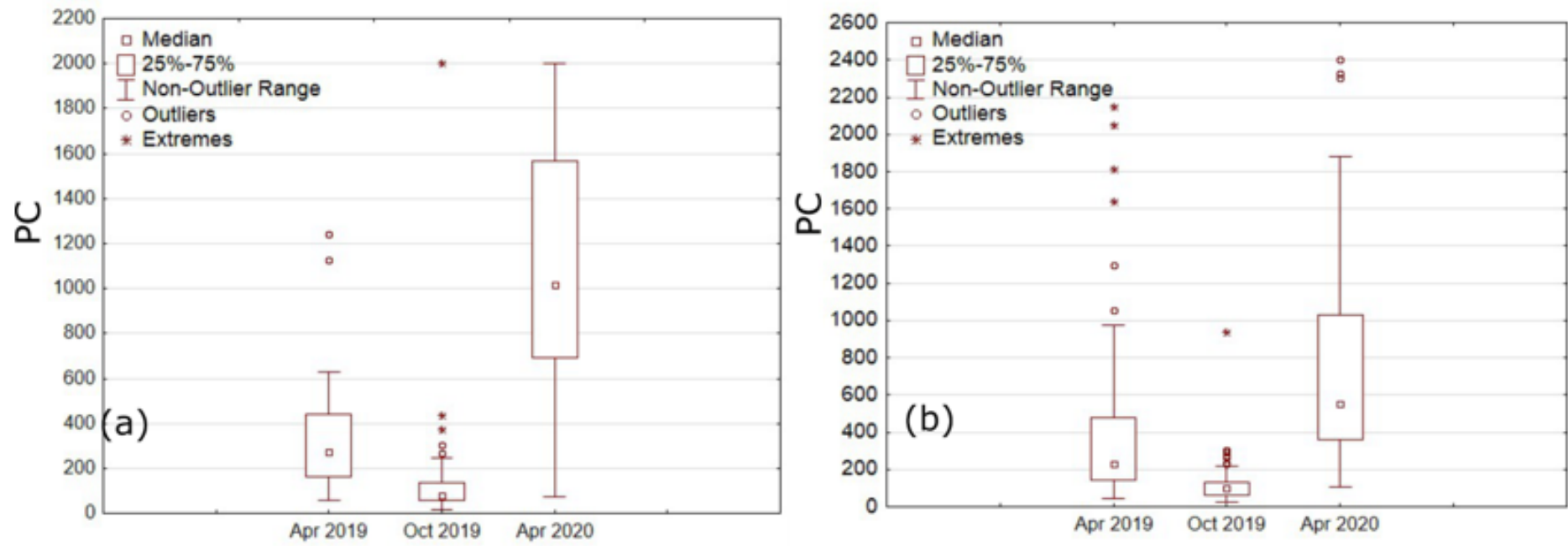

Figure 6

Boxplot for PC concentration ( $\mu \mathrm{g} / \mathrm{L}$ ) in (a) Guarapiranga and (b) Billings reservoirs. 